\title{
The burden of paediatric asthma is higher than healt professionals think: results from the Asthma In Real Life (AIR stud
}

\author{
David Price, Dermot Ryan, Linda Pearce, Robert Bawden, Daryl Freeman, Mike Thomas, \\ hee Robso
}

Abstrac

Aim firo assess perceptions of children with asthma, parents o children with asthma and Health Care Professionals (HCPs) o dsthma symptoms, lifestyle impairment, perceived control an treatment effects using the dataset provided within the AIR study ${ }^{1}$ Method Questionnaire based survey of 687 parents of children age 8-14 with asthma, 579 children aged 9-14 with asthma and HCP treating asthma (401 practice nurses and 809 GPs).

Results: Symptom frequency in patients was higher than expected b HCPs, as was reliever use - with $45 \%$ of patients using reliever three times per day. $65 \%$ described their asthma as "well controlled yet of these: $37 \%$ had difficulty breathing, $34 \%$ nocturnal waking 29\% dry cough and $29 \%$ ability to talk adversely affected by asthm at least weekly

Conclusions HCPs underestimate asthma symptom prevalence an bfestyle limitation. Many children with asthma and parents appear t derceive significant levels of symptoms, lifestyle restriction an reliance on reliever medication as good control. This perceptio needs to be challenged if progress is to be made in improving patien outcomes

\section{David Pric \\ GPIAG Professor o \\ Primary Care Respirator Medicin \\ Dermot Rya \\ General Practitione \\ Introductio \\ The aims of asthma treatment in children are $t$ maintain patients as symptom-free as possible eninimise exacerbations, relief treatment usag activity and lifestyle limitation whilst maintaining o improving lung function ${ }^{2}$,}

Cinda Pearc

Respiratory Nurs

Consultan

Robert Bawde

General Practitione

Daryl Freema

General Practitione

\section{Mike Thoma}

General Practitione

hee Robso

Merck Sharp \& Dohm

Correspondence to Erofessor David Pric Dept of General Practic and Primary Care

University of Aberdeen Foresterhill Healt Centre, Westburn Road Aberdeen AB25 2AY

Tel: 01224552427

d.price@abdn.ac.uk

Date Submitted:02/04/0 Date Accepted: 03/05/0

Prim. Care Respir 2002 )1(2 30-3
Bccurrence of asthma symptoms despite treatment ha been blamed on inadequate or improper prescribing o poor adherence with preventive, anti-inflammator gherapies. Although preventive therapy prescribin has increased greatly over the last few year ${ }^{4}$ this ma hot solve all the problems of asthma as additiona strategies may be needed to help overcome poo sdherence which is present in up to $50 \%$ of patient with asthma ${ }^{5}$

Several studies have shown asthma symptoms ar common in children ${ }^{8-}$ kut there is much less wor exploring the impact of asthma on their daily live and virtually none comparing this with HCPs perceptions. This study explores the impact o ansthma in children - in terms of symptoms, impact o normal activities and perceptions of asthma control ft also assesses whether asthma symptoms might $b$ related to reported under-use of preventive therapies.

Finally, the study compared what aspects of asthm children and their parents rated as being important with factors considered important by HCPs. Th great majority of patients with asthma are manage dntirely within general practice, so practice nurses an GPs attitudes were investigated

\section{Method}

The data for this study was obtained from an analysi of the paediatric subset of the AIR study ${ }^{1}$ gurin August and September 1997. Over 90\% of primar aare prescriptions in the UK are dispensed by dommunity pharmacist. All children aged 8 to 14 an parents of younger children or parents who wer onaccompanied by their children were asked $t$ aomplete questionnaires on-site about their asthm treatment and symptoms when they collected asthm smedication from 800 randomly selected pharmacie ghroughout the United Kingdom. Others collectin acripts were excluded from the study, as were childre whose parents stated the medication was not fo asthma. Children over the age of 8 were allowed $t$ complete the questionnaire with parental assistance Recruitment was undertaken in pharmacies rather tha GP surgeries and over a three month period $t$ minimise severity bias

Following pilot studies, questionnaires wer developed by the authors for completion by parent and children containing questions addressing th following issues

- Asthma duration

- Current treatmen

- How often inhalers use

- Which inhaler they felt helped most and serceived benefit

- Whether they deliberately administer or take less dreventer treatment than advise

- Frequency and presence of asthma symptoms: dry cough, tight chest, nocturnal waking due to asthma and difficulty talking due to asthma

- Open questions to find out difficulties and limitations experienced on 'bad asthma days'

- Perceived overall asthma contro

Asthma therapy was classified into relievers (short acting $\beta \mathrm{e} 2$-agonists), preventers (inhaled steroids an cromoglycate) and controllers (long-acting $\beta-2$ agonists and xanthines). Leukotriene antagonist were not included as this study was undertaken prio to their launch in the UK

The health professional study was based on telephon interviews with 401 practice nurses involved $\mathrm{i}$ hsthma management and face-to-face interviews wit 809 GPs. GPs were sourced using Taylor Nelso Sofres weekly GP omnibus, Omnimed, which carrie 
dut regular face-to-face interviews with GPs. GPs an practice nurses were chosen to be a nationall representative sample and were asked about thei perceptions of patients' asthma symptoms and thei beliefs about asthma treatment. Questions als 'covered how they considered asthma affected patients lifestyles and how they defined 'bad asthma days'.

\section{Result}

\section{Batient}

A total of 579 children aged 8 to 14 years, agreed $t$ somplete questionnaires with parental assistance a required. The parents of a further 687 children age 0-14 years, also agreed to complete the questionnair to give a total of 1266 responses. Non-response rate are unknown given the nature of pharmacy practice $\$ 1.7 \%$ of these children were male. Most children ha an asthma diagnosis for between 1-5 years, apart fro very young study participants.

\section{Asthma treatmen}

Rarents and patients stated that $25 \%$ received reliever without a preventer (33\% of under $5 \mathrm{~s}$ an $24 \%$ of those 5 and over); $61 \%$ received a prevente without additional controller therapy $(56 \%<5$ years $62 \%=5$ years); $12 \%$ received a preventer an additional controller treatment $(7 \%<5$ years, $13 \%=$ years). $2 \%$ of patients received unclassifiable therap such as theophylline as sole therapy

\section{Asthma symptom}

Reported symptom frequency was similar across ag groups and whether reported by parents or childre and is presented in table $1.60 \%$ reported difficulty $i$ breathing at least once a month, with simila proportions suffering nocturnal waking (52\%), dr sough $(51 \%) ; 47 \%$ said that their ability to talk wa fffected by asthma at least once a month. $29 \% \mathrm{o}$ ohildren suffered dry cough or found their ability $t$ talk affected by their asthma at least once a week while $34 \%$ reported nocturnal wakening and $37 \%$ ha difficulty in breathing.

HCPs suggested lower rates of these symptoms tha seported by patients. GPs and practice nurse

\begin{tabular}{|c|c|c|c|c|c|}
\hline \multicolumn{6}{|c|}{ Table 1. Reported symptom frequenc } \\
\hline & $\begin{array}{c}\geq \\
\text { Daily } \\
\% \\
\%\end{array}$ & $\begin{array}{c}\geq \\
\text { Weekl } \\
\% \\
\%\end{array}$ & $\begin{array}{c}\geq \\
\text { Monthly } \\
\% \\
\%\end{array}$ & $\begin{array}{c}\text { Neve } \\
\% \\
\end{array}$ & $\begin{array}{r}\text { No } \\
\text { 8tate } \\
\% \\
\end{array}$ \\
\hline $\begin{array}{l}\text { Asthma wake } \\
\text { you/them } i \\
\text { the nigh }\end{array}$ & $\theta .5$ & B4. & ब2. & 06. & 0 . \\
\hline Dry coug & 6.5 & 09. & б1. & 02. & ๑. \\
\hline $\begin{array}{l}\text { Difficulty i } \\
\text { greathin }\end{array}$ & 0.5 & $\theta 7$. & 60. & $\theta$. & ๑. \\
\hline $\begin{array}{l}\text { ststhma affect } \\
\text { kbility to tal }\end{array}$ & 5.4 & 09. & $\theta 7$. & 03. & $\theta$. \\
\hline
\end{tabular}
helpful

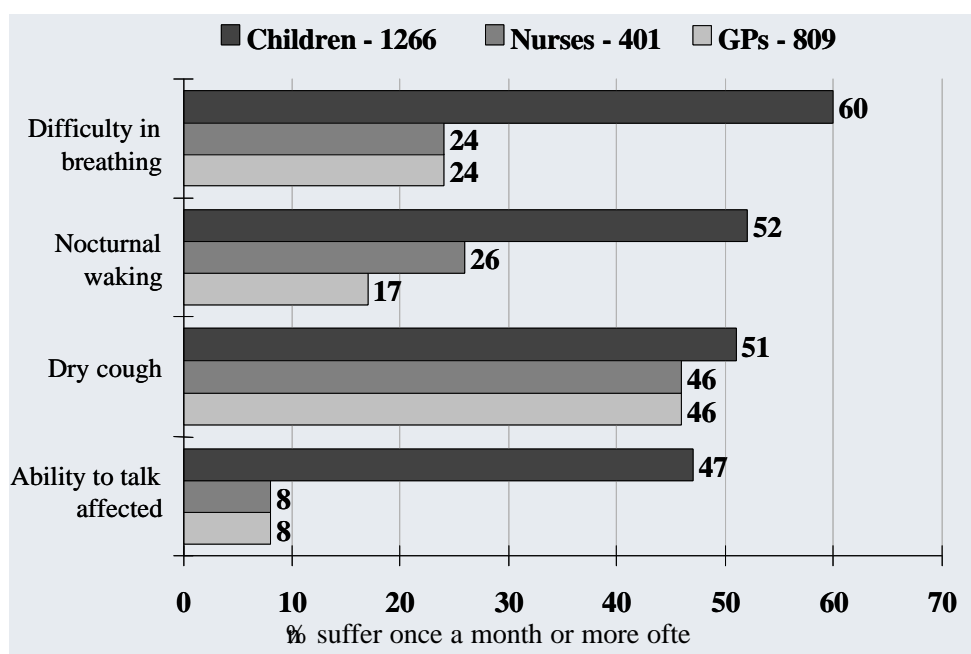

Figure1: Symptom prevalence at least once a month - comparison o statements of children and parents with views of health care professional

Estimated difficulty in breathing affected $24 \%$ o patients at least monthly and that ability to talk woul be affected in only $8 \%$ of patients. Practice Nurse were slightly more aware of the level of nocturna waking, estimating it affected $26 \%$ of patients compared to GPs who thought that it affected $17 \%$ Both groups had a more accurate estimation of $\mathrm{dr}$ cough, estimating that it affected $46 \%$ of patients a least monthly (figure 1).

Perception of inhaler usage and benefi

Parents and children with asthma perceived tha reliever medication was the most helpful treatment $65 \%$ of children and $56 \%$ of parents stated tha reliever inhalers helped asthma the most Approximately one-quarter (22\%) of children an parents considered preventer inhalers to be mos

HCPs' perception of preventer inhaler benefit whe gomplied with was at variance with that reported $b$ parents and children - with 52\% of patients/parent stating when they complied with their preventer the still suffered symptoms (practice nurses - 19\%; GPs $20 \%)$.

More respondents (42\%) admitted taking les preventer therapy than recommended and thi proportion was more than HCPs though (practice nurses - 30\%; GPs - 36\%).

HCPs also underestimated how many childre felt they needed their reliever inhaler mor than the guideline aim of less than daily (50\% of children vs. practice nurses $27 \%$ an GPs 30\%).

Mean daily reliever usage was reported at 2 . times a day. Results showed greater $\beta-2$ figonist use was not associated with lack o preventer medication. In fact, children wh used a preventer reporting using $\beta$ s2-agonist 


\section{Driginal Researc}

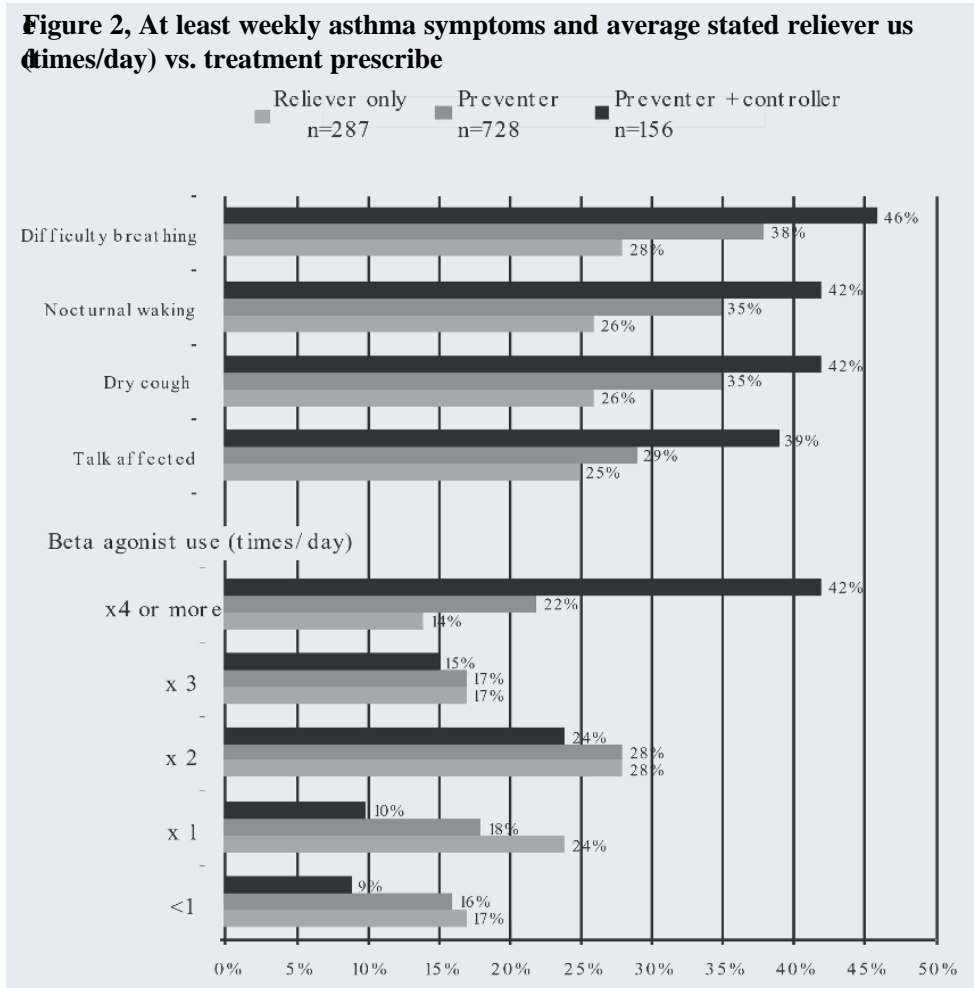

ITable 2. Patients' asthma symptoms versus perceived level of asthma contro

\begin{tabular}{|c|c|c|c|c|c|}
\hline & $\begin{array}{c}\text { Total } \\
\text { Base: } 126\end{array}$ & $\begin{array}{c}\text { Completel } \\
\text { Base: } 20\end{array}$ & $\begin{array}{c}\text { Wel } \\
\text { Base: } 82\end{array}$ & $\begin{array}{r}\text { Not wel } \\
\text { Base: } 20\end{array}$ & $\begin{array}{c}\text { Not at al } \\
\text { well Base: } 1\end{array}$ \\
\hline $\begin{array}{l}\text { Difficulty i } \\
\text { greathin }\end{array}$ & $\theta$ & $\bar{B}$ & 9 & 8 & 9 \\
\hline $\begin{array}{l}\text { Nocturna } \\
\text { gVakin }\end{array}$ & 8 & 2 & 5 & 7 & $\mathbb{0} 0$ \\
\hline Dry coug & $\$$ & 3 & $\boldsymbol{\theta}$ & 7 & 8 \\
\hline $\begin{array}{l}\text { Ability to } \\
\text { thlk affecte }\end{array}$ & 49 & $\begin{array}{c}4 \\
\text { atients expe }\end{array}$ & $\begin{array}{c}6 \\
\text { encing it }\end{array}$ & $\frac{4}{4}$ & $\begin{array}{c}\theta \\
\text { r more ofte }\end{array}$ \\
\hline
\end{tabular}

ITable 3. Relief treatment usage vs. stated asthma contro

\begin{tabular}{|c|c|c|c|c|c|}
\hline & $\begin{array}{c}\mathrm{h}=126 \\
\%\end{array}$ & $\begin{array}{c}\text { Completel } \\
\qquad \begin{array}{c}\mathbf{h}=\mathbf{2 0} \\
\%\end{array}\end{array}$ & $\begin{array}{c}\tilde{\mathbf{n}}=82 \\
\%\end{array}$ & $\begin{array}{c}\mathbf{6}=\mathbf{2 0} \\
\%\end{array}$ & $\begin{array}{c}\text { Not at all } \\
\text { wel } \\
\mathbf{5}=1 \\
\%\end{array}$ \\
\hline 44 or mor & 3 & 5 & 0 & 8 & $\theta$ \\
\hline $\mathbf{z}$ & 1 & 9 & $T$ & 3 & $\$$ \\
\hline 8 & 8 & 3 & $\theta$ & 3 & 3 \\
\hline $\mathbf{t}$ & 8 & 4 & $\Phi$ & 2 & $\$$ \\
\hline Non & $\$$ & $\theta$ & 4 & 5 & 0 \\
\hline
\end{tabular}

slightly more frequently than those receiving relieve therapy alone. These rates were further increased $\mathrm{i}$ those taking a preventer plus additional controlle therapy (figure 2)

Similarly increasing severity of asthma symptom showed a pattern of increased use of preventer therap and other controller therapy (figure 2). smpact of asthma on activitie

Half of the children $(51 \%)$ reported they could not $d$ everything those without asthma could - HCP expectations were at slight variance (practice nurses 38\%; GPs - 41\%). Underestimation of specific thing children were prevented from doing was greater - fo dxample $53 \%$ of children reported having to avoi tontact with animals, while practice nurses though this would affect $29 \%$ and GPs $25 \%$.

The free text section where patients described th impact of a 'bad asthma day' showed the commones problem was inability to participate in sport, to pla games or take part in physical education, reported $b$ ฉ7\% of children; playing with friends $22 \%$, running o jogging $17 \%$; going to school $12 \%$ and disturbed slee $6 \%$. GPs and practice nurses reported symptom predominantly rather than activities in response to thi question

\section{Perceived asthma contro}

$81 \%$ of respondents described their own, or thei ghild's asthma as well controlled or completel kontrolled with $16 \%$ considering asthma not wel tontrolled. However, symptoms and relief treatmen ssage appeared poorly related to how well patient bonsidered their asthma was controlled. Of the 82 children who considered their asthma well controlled $59 \%$ suffered difficulty in breathing at least once thonth, $51 \%$ nocturnal waking, $50 \%$ dry cough an $\$ 6 \%$ their ability to talk affected (table 2). Similarl deliever usage bore little relationship to perceive asthma control with $15 \%$ of those stating they wer eompletely controlled using relief treatment 4 or mor times a day (table 3)

\section{Discussio}

One potential drawback of this study is that the rate $o$ eon-responders is unknown although the ag distribution of responders prescribing patterns an relief treatment usage were consistent with that foun in the authors' practice ${ }^{1}$ and outcomes reported i other surveys ${ }^{\boldsymbol{\theta}-} \mathbf{t}$ is also not possibleto assess th oomparitive effects of the telephone versus face $t$ face interviews utilised in this study. Furthermore dithout direct knowledge of the information provide to patients by their physician we cannot explain th instances of conflicting results from patients an health professionals. For example, the comparativel bigh rate of reported avoidance of animals by th shildren to those predicted by the health professional may be explained by instructions to the children $t$ avoid contact. Whilst quantitative comparison between the views of HCPs and patients or parent should therefore be viewed with caution other finding degarding patients views on treatment, symptoms an asthma control are important even if they apply to substantial subset of patients

This community-based study of children with asthm tevealed a high level of asthma symptoms and impac on normal activities, despite apparently appropriat prescribing consistent with several previous surveys o patients with asthma ${ }^{\text {}-}$ 
Patients generally considered that they had goo asthma control despite levels of symptoms and relieve yse that suggested the contrary. Results suggest man children required excessive $\beta \mathfrak{f} 2$-agonist relie treatment, with many using them at least four time daily, while guidelines suggest that they should ideall be needed less than daily ${ }^{2}$ This did not appear to $b$ due to lack of prescribing of preventer therapy. In fact ahildren taking preventer medication, or taking preventer plus an additional type of asthma therapy tended to use more $\beta \mathrm{e} 2$-agonists and suffer mor symptoms than those on only reliever therapy. Thi mdicates that there is a lack of asthma control $i$ ehildren of all levels of asthma severity that is mor marked in those with more severe disease ${ }^{\mathbb{1}}$ Interestingly, many patients reported that even whe they adhered fully with preventer therapy it did no fully control their asthma. Whilst adherence was no fully formally assessed in the study, many patient admitted to taking less preventer therapy tha recommended and this perception may be one reaso for this. HCPs appeared to underestimate ho frequently children were using reliever inhalers.

Bne positive point was both children and HCP meported cough as a common asthma symptom, as previous study suggested this symptom was often no reported by children with asthma ${ }^{\oplus}$ However, it is o yoncern that health professionals generall underestimated the prevalence of asthma symptoms

It is of note that this study revealed a far highe percentage of children using preventer treatment $(60 \%$ than a similar European wide study where th percentage was between 26 and 34\% althoug recruitment methods were different ${ }^{1}$ The figure $\mathrm{i}$ this study is consistent with that seen in U prescribing databases and suggest guideline advise o use of antiinflammatory agents is being followed

The findings support differences found in other wor between what HCPs and patients perceive of a 'health'. HCPs tend to define 'health' on a medica model, as an absence of illness or symptoms. I sontrast, patients tend to focus on concepts such a 'being able' or 'looking after yourself. ${ }^{\mathcal{L}}$ The danger o this has been emphasised by a recent study tha revealed some children with asthma at risk for poo self-concept associated with negative attitudes toward their illness 13

This study taken in conjunction with other publishe work in this area suggests a number of ways asthm outcomes might be improved.

Firstly, we need to be careful not to accept parents o children's statements that their asthma is wel gontrolled as this study shows that whilst superficiall it may be so in reality if we probe deeper, asthm eontrol in many children will be revealed to $b$ relatively poor.

Secondly, it may be necessary to redefine what i meant by asthma control for children and their parents It might be helpful to ask children about their ability rake part in activities that they want to include in thei daily lives, such as exercise and playing with friends in order to more accurately define and assess asthm ontrol i.e. what does your asthma prevent you fro doing
Frinally, there seems to be a gap in communicatio between patients and HCPs as demonstrated $b$ mpparent underestimation of asthma sympto prevalence and reliever medication usage by HCPs Children with asthma also defined 'bad asthma days differently to HCPs. GPs and practice nurses focuse on symptoms, while patients focused on activit kimitation. Communication may improve if HCPs tak more account of outcomes that are important an relevant to patients. Peak flow rates and inhaler us hre useful indicators, but a patient-focused approac should additionally include measures such as limitatio of activities. If consultations offer the prospects o achieving changes that are meaningful to patients, th therapeutic partnership might become more effective.

\section{Acknowledgement}

The authors would like to thank everyone involved i the study - parents and children taking part in th survey, pharmacies where the study was carried out study analysers and funders. This study was sponsore by an educational grant from Merck Sharp \& Dohme and the survey conducted by Taylor Nelson Sofre under the guidance of the authors.

\section{Reference}

1. Price D, Ryan D, Pearce L, Bride F. The AIR Study The Asthma Journal, 1999; ( \&:74-7

2. British Thoracic Society, British Paediatri Association, Research Unit of the Royal College o Physicians of London et al Guidelines on th

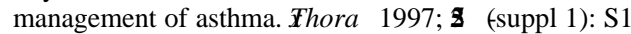
$\$ 2$

3. Global Initiative for Asthma (GINA). Pocket Guid for Asthma Management and Prevention. NI

Publication No. 96-3659B. Bethesda, MD: Nationa Bnstitutes of Health. 199

9. Prescription Pricing Authority. Practice Prescribin gnd Spending on COPD Drugs. Prescription Pricin Authority 2000

5. Dekker, FW, Dieleman FE, Kaptein AA, Mulde

JD. Compliance with pulmonary medication in genera practice. Eur Respir 1993; 60886-89

6. The Life Quality of Asthmatics. 1990. Applie

Research and Communications Ltd, Londo

Æ. National Asthma Campaign. The needs of peopl

Qvith asthma study. 200

8. National Asthma Campaign. Impact of asthm

Gurvey. 199

๑. The Health Survey for England 1996. Th

Stationery Office 1998

A0. Aothacroftominb, Swystun

versus asthma severity IJ Allergy Clin Immuno 1996881016

t1 1. Falconer, A, Oldman, C, Helms, P. Poor agreemen hetween reported and recorded nocturnal cough i asthma. Pediatr Pulmono 1993 \$ 1209-21

.12. Rabe K.F., Vermeire P.A., Soriano J.B., Maier W.C Clinical management of asthma in 1999: the Asthm Insights and Reality in Europe (AIRE) study. Eu Respi $20006: 802-807$

\section{StClaire, L., Watkins, C.J., Billinghurst, B}

Differences in meaning of health: an exploratory stud of general practitioners and their patients. Fam Prac $199636511-51$

14. McNelis, A.M., Huster, G.A., Hollingsworth

M.M., et al Factors associated with self-concept i children with asthma. $d$ Child Adolesc Psychiatr Nur 2000 13(2 855-6 